\title{
Effects of Consumer Consumption Value and Psychological Status on Cosmetics Repurchase Behavior in the COVD-19 Era
}

\author{
Ji Young Lee ${ }^{1}$, Jung Min Lee ${ }^{2}$, Sungkwan $\mathrm{An}^{{ }^{1 *}}$ \\ ${ }^{1}$ Department of Cosmetics Engineering, Konkuk University, Seoul, Korea \\ ${ }^{2}$ Nature Blue Inc., Incheon-si, Korea
}

\author{
"Corresponding author: Sungkwwan An, \\ Department of Cosmetics Engineering, \\ Konkuk University, 120 Neungdong-ro, \\ Gwangjin-gu, Seoul 05029, Korea \\ Tel.: +82 24504054 \\ Fax: +82 5027702278 \\ Email: ansungkwan@konkuk.ac.kr
}

\section{Received July 19, 2020}

Revised August 18, 2021

Accepted September 17, 2021

Published September 30, 2021

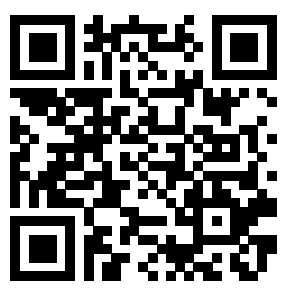

\begin{abstract}
Purpose: This study examines the effect of changes in the daily lives of cosmetic consumers resulting from COVID-19 on behavioral intention according to consumption value and analyzes the relationship among consumption value, purchase satisfaction, and repurchase intention of cosmetic consumers. Methods: In this study, a collected questionnaire was statistically processed to verify the established hypothesis, and through the data coding process, empirical analysis was performed using the SPSS (Statistical Package for Social Science) 22.0 program and Amos 21.0. Results: As a result of examining the effect of cosmetic shopping value on satisfaction and expected regret, based on the independent variable, rare consumption value ( $C R=5.199)$, hedonistic consumption value ( $C R=6.974)$, and functional consumption value $(C R=4.214)$ on satisfaction, ethical consumption value ( $C R=15.628)$ and functional consumption value $(C R=2.798)$ were found to affect the expected regret $(p<0.01)$. As a result of the hypothesis testing, the most influential section was the effect of satisfaction on repurchase (C.R.=27.117). Conclusion: This study analyzed the data of 1,059 people and confirmed the effect of the change in consumption value on consumer satisfaction as the center of consumption shifts rapidly from offline to online due to the influence of the untact era. It is thought that this understanding would be helpful in establishing effective strategic technology.
\end{abstract}

Keywords: Consumption value, Covid-19, Expected regret, Repurchase behavior, Satisfied

\section{Introduction}

'21년 7월 현재, COVID-19으로 인해 마스크를 의복처럼 착용하 고, 습관처럼 사회적 거리 두기(social distancing)를 하며, 중앙방역 대책 본부의 브리핑을 매일 같이 확인하는 것이 새로운 일상이 되어 버렸다(Lee \& You, 2020). COVID-19는 New Normal로 자리잡으며 국내외 경제를 위축시키고 사람들의 소비방식까지 바꾸어 놓았다. 이 러한 변화는 크게 두가지로 요약할 수 있다. 첫째, 소비의 중심이 오 프라인에서 온라인으로 급격하게 이동하였다. 오프라인 소비를 선호 하던 계층들도 반 강제적 온라인 소비 경험에 익숙해지고 있으며, 게 다가 온라인 구매 경험을 가지고 있는 소비자들은 오프라인 구매보다 온라인 구매에서 더 큰 만족을 느끼고 온라인에서 재구매하는 경향이 두드러진다(Khalifa \& Liu, 2007)는 연구결과는, 향후 온라인 소비가
당분간 강세를 보일 것이라는 예상을 뒷받침한다. 이 중 화장품 소비 에 대해 상세히 살펴보면, 마스크 착용과 재택근무, 다수의 인원의 모 임 금지 등으로 절대적인 수요가 감소하였고, 특히, 국가간 이동제한 등의 여파로 외국관광객의 국내 유입이 줄어들면서 면세점을 비롯한 백화점, 로드샵 등 주요 오프라인 상권 매출은 더 큰 타격을 입었다. 이후 확진자 감소에 따른 거리두기 완화 등으로 화장품 소비 수요는 점차 회복되었으나, 타 상품 군에 비해서 소비자가 오프라인 구매 보 다는 온라인 구매를 선호하는 현상이 두드러졌다(Kim, 2021a). 둘째, 소확행(작지만 확실한 행복), 가심비(심리적 만족), 욜로(현재 자신의 행복을 가장 중시하고 소비하는 태도)등 ㅎ⽄ㅍ 소비가치행동이 등장하 게 된다. 즉, $\mathrm{COVID}-19$ 로 인해 건강, 안전, 환경, 행복, 가족 등 개인 의 행복 가치를 중시하는 life style이 보편화 되었으며, 사람들은 자기 만족과 행복을 얻을 수 있고 COVID-19의 불안감을 덜어주는 소비형 
태를 선호한다(Hwang \& Kim, 2020). 화장품의 경우 명품브랜드 제 품의 소비증가가 대표적인 현상이며, 이는 소비자의 기본적인 욕구와 목표의 표현인 소비가치의 변화가 구매행동에 영향을 준 것이다. 현 대백화점에 따르면, 자사 온라인 몰의 '21년 1월 명품브랜드 상품 매 출이 전년 동기보다 12.9 배 증가했는데(Hong \& Nam, 2021), 이 중 약 $30 \%$ 는 명품 브랜드 화장품이 차지하고 있다. 이러한 변화를 감지 한 백화점과 면세점 업계는 그동안 오프라인 매장 중심으로 고가 명 품브랜드 화장품을 판매하던 형태에서 온라인 판매 강화 전략으로 선 회하였다. 롯데백화점(롯데닷컴)은 온라인에서 상품을 주문하면 3시 간 이내에 배송하는 '바로 배송'서비스를 제공하고 있으며, 신세계면 세점은 카카오톡 플랫폼에 입점하여 판로를 넓히고 있다. 또한, 자사 의 온라인 사이트를 서비스 중심으로 대대적으로 개편함으로써 기존 고객을 유실하지 않고 신규고객을 유치하는데 힘쓰고 있다. 결국, 소 비자가 자주 방문하는 곳(온라인)에 잘 팔리는 상품(명품브랜드 화장 품)을 가져다 놓는 것(Choi, 2020)이 업계의 통상적인 전략인 것이다.

본 연구는 COVID-19인한 화장품소비자의 일상생활의 변화가 소 비 가치에 따른 행동 의도에 미치는 영향을 알아보고, 화장품소비자 의 소비 가치, 구매만족도 및 재구매의도의 영향관계를 분석함으로 써, 온라인화장품쇼핑몰에서 소비자와의 관계를 강화할 수 있는 전 략적 제언을 하고자 하였다. 이론적으로 소비가치는 소비자의 행동 을 이해하는 유일한 방법이라 할 수 있으며 소비자들은 자신의 경험 과 주변 평판 또는 이미지로 내재된 가치를 통해 자신이 가지고 있 는 가치가 충족되는 제품 및 서비스의 일치성에 따라 구매행동을 하 게 된다(Gallarza \& Gil, 2006). 소비 가치는 소비자가 달성하고자 하는 기본적인 욕구와 목표의 표현이자 소비자 개인의 사고와 행위 를 이끌어 가는 지속적인 신념(Won \& Chung, 2015)을 말하며, 자 기만족을 위해 소비행위를 하지만 타인에게 보이기 위한 소비 행위 도 한다(Chung, 2015). 마케팅 분야에서의 소비 가치는 제품의 소비, 구매 등과 관련되어 제품이나 서비스에 대한 소비자의 평가와 관련 된 개념으로 사용된다(Zeithaml, 1998). Sheth et al. (1991)는 앞선 Rokeach (1973)의 연구에서 나타나고 있는 광범위하고 추상적인 소 비 가치의 체계와 특성에 대한 한계를 판단하고 경제학, 심리학 등의 다양한 이론을 통합하여 기능적 가치, 사회적 가치, 상황적 가치, 정 서적 가치, 진귀적가치와 같이 5 가지 소비 가치 개념을 제시하였다. 본 연구에서는 복잡하고 다양한 소비 가치 구조를 Sheth et al. (1991) 이 제안한 소비가치이론을 통해 기능적, 경제적 차원에서의 효용가 치뿐만 아니라 정서적 측면과 진귀적 가치, 상황적 가치까지 반영하 여 소비 가치를 포괄적으로 다루고자 했다. Sheth et al. (1991)의 다 섯 가지 소비 가치 중 상황적 가치는 특정 상황에 발현되는 가치이므 로 일반적인 구매행동을 설명하는데 부적절하다(Park \& Kim, 2006; Oh, 2020)는 선행연구들의 지적에 따라, Sheth et al. (1991)의 다섯 가지 소비 가치 중 상황적 가치를 제외하고, Holbrook (2005)의 이타 적 가치 중 윤리를 추가하여 기능적 가치(가격, 품질), 쾌락적 가치, 사회적 가치, 진귀적 가치, 윤리적 가치(환경, 지역사회, 기업의 사회
적 책임)의 다섯 가지 가치를 연구에 적용하였다.

\section{Methods}

\section{1. 연구 대상자 및 기간}

자료 수집은 2021년 7월 1일부터 2020년 7월 13일까지 약 2주 동 안 진행되었다. 연구 대상자는 1,059 명의 전국 20 대- 60 대 여성으로 최근 6 개월 내에 화장품구매경험 대상으로 진행되었다. 남성은 화장 품 구매와 관련 행동이 여성보다 상대적으로 낮게 나타나므로, 화장 품 구매 후 만족 및 예상된 후회의 경험 비율 역시 여성들보다 높지 않을 것으로 판단되어 연구에서 제외하였다.

\section{2. 연구 모형 및 가설}

본 실험은 구조방정식모형을 중심으로 팬데믹 시대의 언택트 소 비경험에 의한 소비 가치의 변화가 소비자의 만족, 예상된 후회에 매 개하여 소비자 구매의도에 미치는 경로를 새롭게 제안하고자 한다. COVID-19 대유행의 영향으로 조금씩 변화해가던 소비자의 소비패 턴은 급변함에 따라, 소비자의 쇼핑 가치와 경험 가치는 기업과의 관 계를 형성하는 중요하며(Hong \& Kang, 2003), Lee \& Shin (2015) 의 연구에 따르면 소비가치유형별로 구매행동에 차이가 있다. 소비 가치는 소비자의 행동을 이해하는 유일한 방법이며. 고객만족은 구매 전 상품에 대한 기대와 구매 후 상품 성과에 대한 소비자의 평가로 정 의한다. 이미 고객 만족을 통한 고객과의 관계증진은 고객의 충성도 를 제고시킨다는 것이 밝혀졌으며, 또한 만족한 고객은 타인에게 호 의적인 구전을 전파하여 신규고객을 창출할 수 있게 해 준다는 것이 밝혀졌다(Fornell \& Larcker, 1981).

1,059 명의 연구 대상자의 소비자 특성(연령, 직업, 소득 등)별 소비 가치 변화와 구매행동의도의 연관성을 분석하고, 만족과 예상된 후회 에 대한 매게 효과를 통해 검증해 본다. 쾌락적 소비가치, 진귀적 소 비가치, 윤리적 소비가치에 미치는 영향을 살펴보고 만족과 예상된 후회의 결과변수로서 그에 따른 재구매의도를 살펴보고자 다음과 같 은 가설을 설정하였다.

$\mathrm{H} 1$ : 화장품소비가치는 만족도에 영향을 줄 것이다.

H1-1: 기능적소비가치는 만족도에 영향을 줄 것이다.

H1-2: 사회적소비가치는 만족도에 영향을 줄 것이다.

H1-3: 쾌락적소비가치는 만족도에 영향을 줄 것이다.

H1-4: 진귀적소비가치는 만족도에 영향을 줄 것이다.

$\mathrm{H} 1-5$ : 윤리적소비가치는 만족도에 영향을 줄 것이다.

$\mathrm{H} 2$ : 화장품소비가치는 후회에 영향을 줄 것이다.

$\mathrm{H} 2-1$ : 기능적소비가치는 후회에 영향을 줄 것이다. $\mathrm{H} 2-2$ : 사회적소비가치는 후회에 영향을 줄 것이다. 
H2-3: 쾌락적소비가치는 후회에 영향을 줄 것이다.

H2-4: 진귀적소비가치는 후회에 영향을 줄 것이다.

H2-5: 윤리적소비가치는 후회에 영향을 줄 것이다.

H3: 만족도와 후회는 재구매에 영향을 줄 것이다.

$\mathrm{H} 4$ : 화장품 소비 가치는 재구매의도에 미치는 간접 효과가 존재할 것이다.

H4-1: 기능적소비가치가 재구매의도에 미치는 간접 효과는 존재 할 것이다.

H4-2: 사회적소비가치가 재구매의도에 미치는 간접 효과는 존재 할 것이다.

H4-3: 쾌락적소비가치가 재구매의도에 미치는 간접 효과는 존재 할 것이다.

H4-4: 진귀적소비가치가 재구매의도에 미치는 간접 효과는 존재 할 것이다.

H4-5: 윤리적소비가치가 재구매의도에 미치는 간접 효과는 존재 할 것이다.

\section{3. 측정도구}

1) 설문지 구성

본 연구에서 COVID-19이후 화장품 소비가치유형이 구매만족도,
예상되는 후회, 재구매의도에 미치는 영향을 알아보기 위해 사용된 설문지는 Homburg et al. (2005), Song (2021), Kim (2021b), Ha \& Lee (2011); Inman \& Zeelenberg (2002), Kim \& Kang (2012)의 선 행연구에서 실시된 측정 항목을 토대로 본 연구의 목적에 맞게 문항 을 수정, 보완하였으며 연구자의 설문을 더하여 제작하여 사용하였 다.

\section{2) 자료분석}

설정된 가설들을 검증하기 위해 회수된 설문지의 통계 처리는 데 이터 코딩 과정을 거친 다음 Statistical Package for Social Science (SPSS) 22.0 Korean version 프로그램과 Amos 21.0을 사용하였다. 인구통계학적 특성은 빈도분석을 하였고 소비가치, 만족도, 예상된 후회, 재구매의도에 항목들의 타당성을 검토하기위해 요인분석을 하 였다. 그리고 연구척도의 신뢰성 검증을 위해 Cronbach's $\alpha$ 값을 보았 다. 또한 즉정변수간의 관계파악을 위해 이변량 상관관계분석, 독립 변수가 종속변수에 미치는 영향에서 매개변수들의 효과를 파악하기 위하여 간접 효과(부트스트래핑 방식)을 사용하여 간접 효과를 파악 요인 별 차이를 파악하기 위하여 $t$-test, two-way ANOVA, 사후분 석으로는 Scheffe를 사용하였다

\section{Results and Discussion}

Table 1. Results of exploratory factor analysis on cosmetic consumption value factor

\begin{tabular}{|c|c|c|c|c|c|}
\hline \multirow{2}{*}{ Questionnaire } & \multicolumn{5}{|c|}{ Components } \\
\hline & 1 & 2 & 3 & 4 & 5 \\
\hline Epistemic value 1 & 0.778 & & & & \\
\hline Epistemic value 2 & 0.708 & & & & \\
\hline Epistemic value 3 & 0.707 & & & & \\
\hline Epistemic value 4 & 0.660 & & & & \\
\hline Ethical value 4 & & 0.923 & & & \\
\hline Ethical value 5 & & 0.897 & & & \\
\hline Ethical value 3 & & 0.887 & & & \\
\hline Social value 4 & & & 0.801 & & \\
\hline Social value 5 & & & 0.775 & & \\
\hline Social value 3 & & & 0.618 & & \\
\hline Hedonic value 3 & & & & 0.755 & \\
\hline Hedonic value 4 & & & & 0.686 & \\
\hline Hedonic value 2 & & & & 0.632 & \\
\hline Functional value 4 & & & & & 0.875 \\
\hline Functional value 5 & & & & & 0.761 \\
\hline Eigen value & 2.699 & 2.290 & 2.290 & 2.132 & 1.566 \\
\hline Explanation variance (\%) & 17.995 & 15.264 & 15.264 & 14.212 & 10.440 \\
\hline Explanation variance (\%) & 17.995 & 50.342 & 50.342 & 64.554 & 74.994 \\
\hline Cronbach $\alpha$ & 0.850 & 0.805 & 0.805 & 0.788 & 0.672 \\
\hline
\end{tabular}


수집된 자료의 신뢰성과 타당성을 조사한 후 $\mathrm{SPSS}$ 와 $\mathrm{AMOS}$ 를 사 용하여 경로 분석과 구조방정식 모델 의 적합성을 분석하여 각 연구 가설과 연구 모형을 검증하였다

\section{Cosmetic consumption value analysis}

본 실험의 독립변수인 화장품 소비 가치는 진귀적 소비가치, 윤리 적 소비가치, 사회적 소비가치, 쾌락적 소비가치, 기능적 소비가치로 요인분석 결과 추출되었다.

측정 도구의 Cronbach's $\alpha$ 값을 보면 모든 변수가 0.6 이상으로 신 뢰성은 확보되었다. 소비가치의 구성요인을 유형화하기 위해 주성 분 분석을 이용하였고, 직각회전의 베리멕스 회전방법을 사용하 였 다. 고유값은 1.0 이상, 요인적재치는 0.4 이상이면 유 의한 변수 로 Table 1같이 추출하였다. 소비가치에 대한 진귀적 소비가치, 윤 리적 소비가치, 사회적 소비가치, 쾌락적 소비가치, 기능적 소비가 치 요인으로 추출 되었다. Kaiser-Meyer-Olkin (KMO)값은 0.895, Bartlett의 구형성 검정치 8537.803 이며, 유의수준이 0.000으로 공 통 요인이 존재한다고 판단되어 요인분석을 위해 적합한 문 항임을 알 수 있었다. 또한 총 누적분산설명력은 $74.994 \%$ 로 나타났다. 세부 적으로는 살펴보면. 소비가치 수준을 유형별로 보면 진귀적 소비가 치의 4 개의 측정 항목의 고유값은 2.699 로 나타나 모두 실험에 진행 되었으며 소비가치 요인중 가장 높은 수준을 보였고, 윤리적 소비가 치의 경우 고유값은 2.562 로 나타나 3 개의 관련 요인으로 선정하였 다. 사회적 소비가치에 대한 분석에서는 모두 3 개의 관련 요인에서 고유값은 2.290 나타났으며, 쾌락적 소비가치의 측정 항목에서는 3 개의 관련요인에서 고유값 2.132 로 파악되었다. 마지막 기능적 소비 가치의 경우 2 개의 관련 문항이 고유 값 1.566 로 나타나 본 실험의 요 인으로 선정되었다.
2. Factor analysis of satisfaction, anticipated regret, and repurchase intention

본 실험의 매개변수 및 종속변수인 만족도, 후회, 재구매의도에 대 한 요인분석 결과는 만족도, 후회, 재구매의도로 모두 3 개의 요인으 로 추출되었다. Table 2 와 같이 고유 값은 1.518 에서 2.475 로 모두가 1.0 을 상회하고 있으며, 모든 변수들이 명확히 분류되었다. 누적 분 산은 $77.424 \%$ 로 나타났으며 요인적재치 역시 모두 0.4 보다 크게 파 악되어 동일요인내의 측정변수간의 집중 타당성과 판별 타당성이 모 두 검증되었다.

$\mathrm{KMO}$ 의 수치는 0.792, Bartlett의 구형성검정치는 4100.68 이고 유의수준이 0.000 으로 공통요인이 존재한다고 볼 수 있어 요인분석 을 위해 적절하다. 탐색적 요인분석의 결과를 살펴보면 재구매는 모 두 3 개의 관련 항목들로 구성이 되었으며 고유값은 2.475로 나타나 재구매요인으로 나타났으며 후회에 대한 분석에서는 모두 3 개의 관 련 항목들로 구성이 되었으며 고유값은 2.201로 나타났으며 만족도 의 경우 2 개의 관련 문항과 고유값은 1.518 로 나타나 만족도 요인으 로 선정을 하였다. 3 개의 요인 모두의 Cronbach' $\alpha$ 값은 0.6이상으로 나와 측정 도구에 문제가 없음을 보여주고 있다.

\section{Confirmation factor analysis result}

전체 인과 모형에 대한 구조 방정식 모형 분석을 하기 이전에 측 정 변수의 판별 타당성과 수렴 타당성은 탐색적 요인분석을 통해 어 느 정도 확인되었으나, 측정 항목에 대하여 요인 별 단일차원성 확 인 및 통계적 검증을 위하여 $\mathrm{AMOS} 21.0$ 을 이용하여 선행 요인에 대 한 확인적 요인분석을 실시하였다. 그 결과는 Table 3 , Table 5 와 같 다. 선행요인들의 특성에 대한 확인적 요인분석의결과 $\chi^{2}=1114.18$, $\mathrm{df}=202, \chi^{2}$ 에 대한 $p$ 값 $=0.000$, 기초적합지수(goodness of fit

Table 2. Results of exploratory factor analysis of satisfaction, regret, and repurchase intention

\begin{tabular}{lccc}
\hline Questionnaire & \multicolumn{1}{c}{ Components } \\
\cline { 2 - 4 } Repurchase 1 & 1 & 2 & 3 \\
Repurchase 4 & 0.864 & & \\
repurchase 3 & 0.838 & & \\
Anticipated regret 4 & 0.780 & & \\
Anticipated regret 5 & 0.660 & 0.909 & \\
Anticipated regret 3 & & 0.868 & 0.883 \\
Satisfaction 2 & & 0.783 & 0.669 \\
Satisfaction 3 & & & 1.518 \\
Eigen value & & & 18.975 \\
Eigen value & 2.475 & 2.201 & 77.424 \\
Explanation variance (\%) & 30.937 & 27.512 & 0.769 \\
Explanation variance (\%) & 30.937 & 58.449 \\
Cronbach $\alpha$ & 0.853 & 0.817 & \\
\hline
\end{tabular}




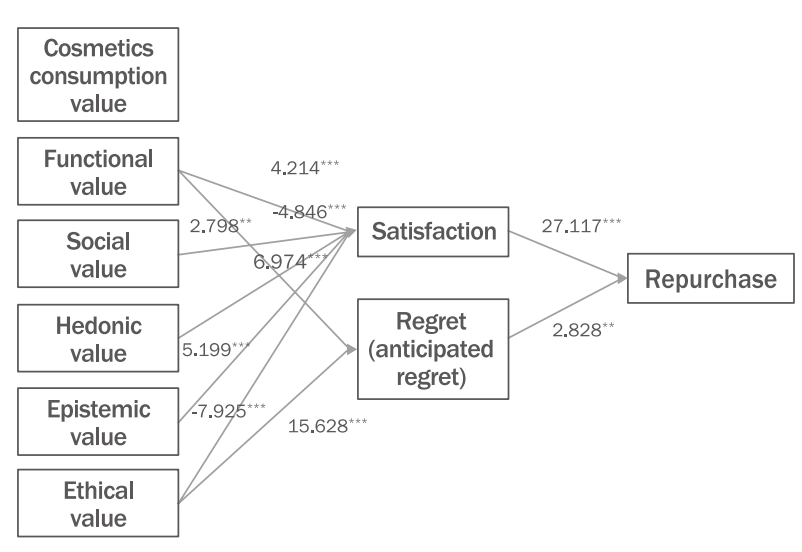

Figure 1. Research model analysis result.

Hypothesis adoption based on C.R value ${ }^{* * *} p<0.001,{ }^{* *} p<0.01$, ${ }^{*} p<0.05$.

연구의 모형은 각 측정 변수의 C.R.가 1.96 을 크게 초과하고, 유의 수준 $p<0.001$ 에서 유의한 것으로 나타났다. 그리하여 집중 타당성이 있다고 판단된다. 따라서 본 연구에서는 수집된 자료를 바탕으로 가
설의 검증이 가능하다.

\section{Hypothesis analysis result}

본 연구의 모형은 8개의 중요변수 즉, 기능적 소비가치, 사회적 소 비가치, 쾌락적 소비가치, 진귀적 소비가치, 윤리적 소비가치, 만족 도, 후회(예상된 후회), 재구매의도로 구성하였다. 연구모형에서 탐 색적 요인분석을 통하여 도출된 요인들로써 확인적 요인분석을 통 해 요인변수들에 대한 타당성이 입증되었다. 개념 타당성을 검증하 기 위해서 적합도를 평가지표로 GFI (0.9이상 우수, 0.8 이상 양호), AGFI (0.9이상), 카이제곱(적을수록 바람직함), 카이제곱에 대한 $p$ 값(0.05이상이면 바람직함)을 적용하였으며 그 결과를 살펴 보면 Table 4, Table 5와 같다. Figure 1은 공분산 구조방정식 모형으로 신뢰성, 타당성 분석에서 제거된 변수들을 제외하고 연구 모형을 토 대로 작성되었다. 연구 모형의 검증 결과를 살펴보면, $\chi^{2}=1143.19$, $\mathrm{df}=208, \chi^{2}$ 에 대한 $p$ 값 $=0.000, \mathrm{GFI}=0.912, \mathrm{AGFI}=0.883$, $\mathrm{CFI}=0.936, \mathrm{RMR}=0.017$, NFI=0.923, Tucker-Lewis index (TLI) $=0.922$, Parsimonious CFI=0.769, Parsimonious NFI=0.759, $\mathrm{RMSEA}=0.065$ 을 나타내고 있다.

Table 3. Cosmetics selection attributes

\begin{tabular}{|c|c|c|c|c|c|c|}
\hline \multicolumn{3}{|c|}{ Division } & \multirow{2}{*}{$\begin{array}{c}\text { Estimate } \\
1.000\end{array}$} & \multirow[t]{2}{*}{ S.E. } & \multirow[t]{2}{*}{ C.R. } & \multirow[t]{2}{*}{$p$} \\
\hline Epistemic value 4 & $<--$ & Epistemic value & & & & \\
\hline Epistemic value 2 & $<--$ & Epistemic value & 0.852 & 0.047 & 17.998 & *** \\
\hline Epistemic value 3 & $<--$ & Epistemic value & 1.068 & 0.049 & 21.886 & *** \\
\hline Epistemic value 1 & $<--$ & Epistemic value & 0.758 & 0.044 & 17.320 & *** \\
\hline Ethical value 3 & $<--$ & Ethical value & 1.000 & & & \\
\hline Ethical value 5 & $<--$ & Ethical value & 1.268 & 0.055 & 23.252 & $* * *$ \\
\hline Ethical value 4 & $<--$ & Ethical value & 1.106 & 0.043 & 25.782 & *** \\
\hline Social value 3 & $<--$ & Social value & 1.000 & & & \\
\hline Social value 5 & $<--$ & Social value & 1.045 & 0.061 & 17.021 & $* * *$ \\
\hline Social value 4 & $<--$ & Social value & 0.976 & 0.060 & 16.274 & *** \\
\hline Hedonic value 4 & $<--$ & Hedonic value & 1.000 & & & \\
\hline Hedonic value 3 & $<--$ & Hedonic value & 0.829 & 0.048 & 17.229 & *** \\
\hline Hedonic value 2 & $<--$ & Hedonic value & 0.992 & 0.054 & 18.485 & *** \\
\hline Functional value 5 & $<--$ & Functional value & 1.000 & & & \\
\hline Functional value 4 & $<--$ & Functional value & 0.722 & 0.070 & 10.331 & *** \\
\hline Repurchase 3 & $<--$ & Repurchase & 1.000 & & & \\
\hline Repurchase 4 & $<--$ & Repurchase & 1.052 & 0.042 & 24.919 & *** \\
\hline Repurchase 1 & $<--$ & Repurchase & 0.680 & 0.036 & 18.716 & $* * *$ \\
\hline Anticipated regret 4 & $<--$ & Anticipated regret & 1.623 & 0.113 & 14.394 & $* * *$ \\
\hline Anticipated regret 3 & $<--$ & Anticipated regret & 1.000 & & & \\
\hline Anticipated regret 5 & $<--$ & Anticipated regret & 1.449 & 0.103 & 14.062 & *** \\
\hline Satisfaction 3 & $<--$ & Satisfaction & 1.000 & & & \\
\hline Satisfaction 2 & $<--$ & Satisfaction & 1.036 & 0.054 & 19.023 & *** \\
\hline
\end{tabular}

S.E., standard error; C.R., critical ratio. 
Table 5 같이 전반적인 적합도 지수 중 GFI는 기준치인 0.90 을 상 회하고 있으며 자유도를 고려한 수정 GFI의 값인 AGFI는 기준치인 0.90을 상회하고 있고, CFI값과 RMSEA값이 모두 기준치를 상회 하 고 있다. 그리하여 전반적 적합도 지수들은 종합적으로 고려할 때 본 모형은 수용할만한 모형임을 알 수 있다.

가설에 대한 분석의 결과를 살펴보면 진귀적 소비가치, 윤리적 소 비가치, 사회적 소비가치, 기능적 소비가치, 쾌락적 소비가치는 모두 만족도에 영향력을 주는 것으로 파악이 되었다. 세부적으로는 윤리 적 소비카치와 사회적 소비가치는 만족도에 미치는 영향은 결과적으 로 윤리적 소비가치와 사회적 소비가치가 높을수록 만족도는 떨어진 다는 것이다, 반면 진귀적 소비가치, 윤리적 소비가치, 쾌락적 소비 가치가 높아질수록 만족도 역시 증가한다는 것으로 해석된다. 소비
자의 구매행동에 관한 연구가 중요한 이유는 구매 후 만족한 소비자 는 가격에 민감하지 않고 높은 가격 프리미엄을 지불할 의사가 있는 것으로 밝히고 있고(Homburg et al., 2005), 이러한 구매 행동은 온 라인 고객 쇼핑행동에서도 온라인 구매자와 판매자간의 장기적인 관 계를 유지하는데 중요한 선행요인으로 나타났다(Szymanski \& Hise, 2000). 본 실험에서는 만족도를 소비자의 온라인화장품 구입 과정에 대한 만족도를 정의하여 측정한 결과 매개 효과를 검증하였다. 예상 된 후회에 미치는 영향력에 대한 분석에서는 윤리적 소비가치와 기능 적 소비가치가 예상된 후회에 영향을 주는 것으로 나타났는데 결과적 으로 윤리적 소비가치, 기능적 소비가치가 높을수록 예상된 후회는 증가한다는 것이다. 또한, 재구매에 미치는 영향력의 경우 만족도와 예상된 후회가 모두 영향력을 주는 것으로 파악이 되었다. 다시 만족

Table 4. Research model structural equation analysis results

\begin{tabular}{|c|c|c|c|c|c|c|c|}
\hline \multicolumn{3}{|c|}{ Analysis } & Estimate & S.E. & C.R. & $p$ & Adopt \\
\hline Satisfaction & $<--$ & Epistemic value & 0.388 & 0.075 & 5.199 & *** & Adoption (+) \\
\hline Satisfaction & $<--$ & Ethical value & -0.308 & 0.039 & -7.925 & *** & Adoption (-) \\
\hline Satisfaction & $<--$ & Social value & -0.338 & 0.070 & -4.846 & $* * *$ & Adoption (-) \\
\hline Satisfaction & $<-$ & Functional value & 0.213 & 0.051 & 4.214 & *** & Adoption (+)) \\
\hline Satisfaction & $<-$ & Hedonic value & 0.703 & 0.101 & 6.974 & *** & Adoption (+) \\
\hline Anticipated regret & $<--$ & Epistemic value & 0.018 & 0.020 & 0.857 & 0.391 & \\
\hline Anticipated regret & $<--$ & Ethical value & 0.238 & 0.015 & 15.628 & *** & Adoption (+) \\
\hline Anticipated regret & $<--$ & Social value & -0.011 & 0.018 & -0.647 & 0.518 & \\
\hline Anticipated regret & $<--$ & Functional value & 0.040 & 0.014 & 2.798 & $0.005^{* *}$ & Adoption (+) \\
\hline Anticipated regret & $<--$ & Hedonic value & 0.000 & 0.025 & 0.012 & 0.990 & \\
\hline Repurchase & $<-$ & Satisfaction & 0.998 & 0.037 & 27.117 & $* * *$ & Adoption (+) \\
\hline Repurchase & $<-$ & Anticipated regret & 0.301 & 0.114 & 2.628 & $0.009^{* *}$ & Adoption (+) \\
\hline
\end{tabular}

${ }^{* * *} p<0.001 ;{ }^{* *} p<0.01 ;{ }^{*} p<0.05$; S.E., standard error; C.R., critical ratio.

\section{Table 5. Research model fit index}

\begin{tabular}{|c|c|c|}
\hline Goodness-of-fit index & Evaluation standard & Model fit results \\
\hline df & Number of available information units after the parameter is estimated & 208 \\
\hline Chi square statistic & - & 1143.19 \\
\hline $\mathrm{p}$ & - & 0.000 \\
\hline GFI & $>0.9$ excellent, $>0.8$ good & 0.912 \\
\hline AGFI & $>0.8$ excellent, $>0.7$ good & 0.883 \\
\hline RMR & minimum & 0.017 \\
\hline $\mathrm{NFI}$ & $>0.9$ excellent, $>0.8$ good & 0.923 \\
\hline TLI & $>0.9$ excellent, $>0.8$ good & 0.922 \\
\hline $\mathrm{CFI}$ & $>0.9$ excellent, $>0.8$ good & 0.936 \\
\hline IFI & The closer to 1 the better & 0.936 \\
\hline Parsimonious CFI & $>0.7$ excellent, $>0.6$ good & 0.769 \\
\hline Parsimonious NFI & $>0.7$ excellent, $>0.6$ good & 0.759 \\
\hline RMSEA & $<0.1$ Adoption, <0.05 optimum & 0.065 \\
\hline
\end{tabular}

df, degree of freedom; GFI, goodness of fit index; AGFI, adjusted goodness of fit index; RMR, root mean square residual; NFI, normed fit index; TLI, Tucker-Lewis index; CFI, comparative fit index; IFI, incremental fit index; RMSEA, root mean square error or approximation. 
도와 후회가 높을수록 재구매는 증가하는 것으로 이해가 된다. 또한, 가장 큰 영향력을 미치는 구간은 만족도가 재구매에 미치는 영향으로 나타났으며 다음으로는 윤리적 소비가치가 예상된 후회에 미치는 구 간으로 나타났다. 예상된 후회(anticipated regret)란 특정적인 사건 이 일어나지는 않았지만 일어난 것으로 생각하여 상상하게 되는 사고 과정에서 경험하는 후회를 말한다(Simonson 1992). COVID-19 사 회적 현상이 장기간 지속되면서, 경험된 감염이라는 부정적 감정의 변수를 측정을 위해 예상된 후회는 온라인쇼핑경험을 불만족하게 하 는 선행 변수로 연구되었으며, Lee \& Cha (2005)의 고객만족에 영향 을 미치는 부정적 소비 감정을 설명하기 위한 매개 감정의 요인으로 사용한 후회의 연구를 차용하여 본 연구에 맞게 측정하였다. 최근에 는 소비자들이 구매과정에서 예상된 후회가 구매결정에 미치는 영향 에 관한 연구가 활발하다(Cooke et al., 2001; Inman \& Zeelenberg, 2002; Pieters\& Zeelenberg, 2007; Simonson, 1992; Tsiros \& Mittal, 2000). 팬데믹 시대의 필연적인 온라인쇼핑을 통해 온라인 몰의 매출은 급등하고 있고, 온라인쇼핑에서 소비자만족이 증가할수 록 이용 의도가 높아진다(Son et al., 2019; Jeong et al., 2018). 소 비자의 구매결정과정에서 느끼는 후회를 최소화하여 고객만족을 높 아지면, 오프라인 유통 채널과 마찬가지로 온라인쇼핑에서도 높은 고객 충성도가 소비자의 재방문을 높이고 이는 시장점유율과 이익에 긍정적인 영향을 주며(Anderson et al., 1994), 재구매행동은 곧 매 출증대로 이어질 것이다. Figure 1과 같이 화장품 구매 만족에 따라 재구매 및 재구매의도에 영향을 미치는 것으로 분석되었다

\section{Indirect effect verification}

본 실험의 독립변수인 기능적 소비가치, 사회적 소비가치, 쾌락적 소비가치, 진귀적 소비가치, 윤리적 소비가치가 종속변수인 재구매 의도에 미치는 간접 효과(indirect)를 검증하기 위하여 부트스트래핑 방식(Bootstrapping, 500 회, $p=0.05$ )을 사용하여 간접 효과를 검증 하였다. Table 6 과 같이 기능적 소비가치, 사회적 소비가치, 쾌락적 소비가치, 진귀적 소비가치, 윤리적 소비가치가 종속변수인 재구매 의도에 모두 간접 효과를 나타내는 것을 확인할 수가 있었다.

\section{Conclusion}

COVID-19로 인한 소비행동은 팬데믹 시대에 지속적으로 변화할
것이며 COVID-19이후 그 변화의 속도는 점차 더 빨리질 것이다. 본 연구는 1,059 명의 연구대상자의 데이터의 실증분석을 통해 변화하 는 화장품소비자의 구매심리를 파악하고, COVID-19으로 인한 화장 품소비가치유형이 구매만족도, 예상되는 후회, 재구매의도에 미치는 영향과 구매만족도와 예상되는 후회가 재구매의도에 미치는 영향에 관한 연구결과를 도출하였다.

본 연구의 주요 결과들을 요약하면 다음과 같다. 첫째, 온라인쇼핑 몰에 대한 화장품소비자의 쾌락적 소비가치, 진귀적 소비가치, 기능 적 소비가치는 화장품 구매 만족도에 영향 관계가 있는 것으로 나타 났다. 현재 자신의 행복을 가장 중시하는 소비를 의미하는 쾌락적 소 비가치, 온라인쇼핑의 편리함과 신뢰할 수 있는 쇼핑몰, 공인된 브 랜드의 영향을 받는 기능적 소비가치, 그리고 새로움의 진귀적 소비 가치를 충족되어야지만 구매 후 만족도가 올라가고 재구매의도에 긍 정적인 영향을 미치는 것으로 분석되었다. 이는 작년에 시작된 백화 점 화장품 몰의 매출의 급상승현상을 설명할 수 있다. 그 동안은 주 요 백화점 본점이나, 명품관에서나 경험할 수 있던 세계 명품 화장품 을 손 동작 하나만으로 선물할 수도, 3 시간만에 배달 받을 수 도 있다 는 신선하고, 재미있는 진귀적 소비가치가 백화점 몰의 명품 화장품 이라는 기능적 소비가치를 만나 소비자의 구매 동기를 이끌어낸 것이 다. 과시를 위한 명품화장품의 구매의 쾌락적 소비가치가 아닌 나의 가치관, 믿을 수 있는 브랜드에 품질에 대한 기능성소비가치가 구매 행동에 영향을 주었음을 나타낸다.

둘째, 화장품소비자의 윤리적 소비가치와 기능적 소비가치는 예상 되는 후회에 영향 관계가 있는 것으로 나타났다. 예상된 후회는 온라 인 쇼핑 시 구매에 부정적 영향을 미치는 요인인 금전적 손실, 개인 정보유출을 선행 변수로 연구되었고, 그 결과 윤리적 소비가치와 기 능적 소비가치가 후회에 유의한 영향을 미치고 있었다. 전문가들은 팬데믹이 종식된 이후에도 온라인쇼핑에 대한 소비는 계속 될 것이라 고 예측한다. 소비트렌드에 따라 소비자의 필요 욕구를 충족하고, 브 랜드의 가치를 지속발전 할 수 있는 전략을 수립하고, 홈페이지나 모 바일 등을 통해 정보교류를 활발히 한다면 고객의 지속된 유입이나, 만족도 및 재구매의도를 높일 수 있을 것이다. 온라인쇼핑에서의 소 비자와의 좋은 관계는 제품에서만이 아니라, 브랜드가 전해주는 신 뢰 가치와 함께 형성된다. 소비자와의 돈독한 신뢰관계가 장기적인 성장을 도모할 수 있을 것이다,

셋째, 화장품 소비자의 만족도와 예상되는 후회 모두 재구매의도 에 모두 긍정적인 영향을 미치는 것을 알 수 있었다. 온라인 쇼핑몰

Table 6. Indirect effect analysis result

\begin{tabular}{lccccc}
\hline Dependent variable & Functional value & Social value & Hedonic value & Epistemic value & Ethical value \\
\cline { 1 - 1 } Repurchase & 0.155 & -0.289 & 0.633 & 0.368 & -0.138 \\
Count value & $0.008^{* *}$ & $0.004^{* *}$ & $0.005^{* *}$ & $0.004^{* *}$ & $0.003^{* *}$ \\
\hline$p$ & & & & &
\end{tabular}

${ }^{* * *} p<0.01 ;{ }^{*} p<0.05$. 
을 이용하면서 경험하는 긍정적 감정적 요소인 고객만족은 화장품에 대한 호의적인 구매의도를 형성하고 나아가 주변 사람에게 추천할 의 향을 형성할 수 있다고 판단된다. 또한 온라인 쇼핑몰의 이용을 저해 하던 예상된 후회가 팬데믹시대의 필연적인 온라인쇼핑경험으로 인 해 해소되면서 구매의도에 긍정적인 조절역할을 하는 것으로 나타났 다. 즉, 소비자는 온라인 쇼핑몰을 이용하면서 화장품에 대한 고객만 족도가 높을수록 제품을 구매할 가능성이 큰 것으로 볼 수 있다

본 연구의 실무적 의미는 팬데믹의 종식 이후, 지속 가능한 발전을 위해 집중해야 할 요소와 전략을 제시한 것에 의의가 있다. 분명 지 금의 소비 가치는 신뢰할 수 있는 온라인쇼핑몰에서 품질 좋은 브랜 드제품을 편하게 받아보는 것이 만족도를 높게 만드는 재구매행동이 다. 여기서 더 나아가 소비자들이 느끼는 오프라인의 소비가치만족 도를 파악하여 온라인쇼핑에서 오프라인쇼핑에서와 같은 재구매 행 동의 충성고객으로 만들 수 있어야 한다. 화장품구매에 대한 만족에 가장 높은 긍정적 영향을 주는 쾌락적 소비가치를 높이기 위해 즐거 움과 재미를 위한 메이크업 따라 하기 이벤트, 기능적 소비가치를 높 이기 위해 고객들의 후기를 더 많이 독려할 수 있는 이벤트, 진귀적 소비가치를 높이기 위한 리미티드 에디션 제품 딜, 나만의 케이스 제 작 이벤트 등 고객이 직접 찾아오게 만드는 매력적인 요인을 통해 경 쟁적 우위를 가질 수 있게 될 것이다.

본 연구의 학문적 의미는 요즘 많은 관심들을 보이고 있지만 시작 점인 MZ세대의 소비형태 연구이다. MZ세대란1980년대 초-2000년 대 초 출생한 밀레니엄 세대와 1990년대 중반-2000년대 초반 출생 한 Z세대를 통칭한다. 2021년 4월 쇼셜 빅데이터 분석에 의하면 최 근 6 개월 급상승 키워드는 미닝아웃(meaning out)이었다. Meaning (신념)과 Coming out (정체를 드러내다) 두 가지가 결합된 단어로, 자기 가치관과 사회적 신념을 적극적으로 드러내는 소비 행위인 MZ 세대의 트렌드를 의미한다. 본 연구 대상자의 1059 명 중 20 대가 445명(42\%), 30대가 226명(21.3\%), 총 671명(63.3\%)으로 구성되었 고, 연구분석결과, 백화점화장품을 구매하는데 기능적 소비가치, 쾌 락적 소비가치, 진귀적 소비자치가 구매만족도에 긍정적 영향을 미 치는 것으로 나타났다. 과시를 위한 명품화장품의 구매가 아닌 나를 위한 재미, 즐거움, 가치관, 품질에 대한 소비 가치가 현재 많은 관심 을 받고 있는 MZ세대 소비 트렌드에 대해 소비자가 중요하게 느끼 는 기능적, 쾌락적, 진귀적, 윤리적 가치들과 구매의도의 영향 관계 의 연구로서도 MZ세대를 중요한 타깃으로 보는 많은 기업 제품과 마 케팅을 기획에 도움이 될 것이라고 사료된다. 본 연구에서는 온라인 쇼핑몰브랜드에 대한 화장품소비자의 소비 가치, 구매만족도, 예상 된 후회 및 재구매의도에 대해 분석하고, 소비가치유형별 차이와 구 매만족도, 예상된 후회의 미치는 영향을 밝힘으로써 팬데믹 종식 이 후 지속 가능한 발전을 위해 집중해야 할 요소와 전략을 제시한 것에 의의가 있다.

본 연구의 후속 연구방향은 다음과 같다. 화장품 구매 시 만족도 에 영향을 주는 변수들을 화장품 구매 시 만족도에 영향을 주는 요인
으로 제품의 품질, 쇼핑몰의 품질, 구매만족도 및 재구매의도의 차이 를 연구하여 새로운 언택트 환경에서 소비자의 경험을 다양한 측면을 살펴봄으로써 구매행동에 대한 폭넓은 이해를 도모하고, 그동안 화 장품산업 분야에서 깊이 있게 다루어지지 않았던 구매행동에 영향을 주는 고객만족과의 관계를 분석하는 연구도 의미있을 것으로 사료된 다.

\section{Author's contribution}

JYL, JML, and SA designed the overall study and wrote the manuscript together. JYL and SWA analyzed the data. All authors read and confirmed the final version of the manuscript.

\section{Author details}

Ji Young Lee (Graduate student), Department of Cosmetics Engineering, Konkuk University, 120 Neungdong-ro, Gwangjin-gu, Seoul 05029, Korea; Jung Min Lee (CEO), Nature Blue, Inc., \#508, Techno Cube, 174-1 Songdodong, Yeonsu-gu, Incheon-si 21984, Korea; Sungkwan An (Professor), Department of Cosmetics Engineering, University, 120 Neungdong-ro, Gwangjin-gu, Seoul 05029, Korea.

\section{References}

Anderson EW, Fornell C, Lehmann D. Customer satisfaction, market share, and profitability: findings from Sweden. Journal of Marketing, 58: 53-66, 1994.

Choi WS. Expressive characteristics \& trends of luxury fashion brand visual merchandising. Journal of Basic Design \& Art, 21: 383-399, 2020.

Cooke A. Meyvis T, Schwartz A. Avoiding future regret in purchase-timing decisions. Journal of Consumer Research, 2: 447-459, 2001.

Fornell C, Larcker DF. Evaluating structural equation models with unobservable variables and measurement error. Journal of Marketing Research, 1: 39-50, 1981.

Gallarza MG, Gil Saura I. Value dimensions, perceived value, satisfaction and loyalty: an investigation of university students' travel behaviour. Tourism Management, 27 : 437-452, 2006.

Hwang KH, Kim HC. The effect of dietary trend changed by COVID-19 consumption value on behavioral intention. 
Tourism Research, 45: 705-727, 2020.

Holbrook MB. Customer value and auto ethnography: Subjective personal introspection and the meanings of a photograph collection. Journal of Business Research, 58: 45-61, 2005.

Homburg C, Koschate N, Hoyer WD. Do satisfied customers really pay more? A study of the relationship between customer satisfaction and willingness to pay. Journal of Marketing, 69: 84-96, 2005.

$\mathrm{Ha} \mathrm{HH}$, Lee Yl. The effects on purchase deferral of choice difficulty and anticipated regret on assortment size of product. Journal of Product Research, 29: 1-10, 2011.

Hong SY, Nam MW. Research on sustainable management strategies of luxury fashion brands in the era of pandemic. The Korean Society of Science \& Art, 39: 519-537, 2021.

Hong ST, Kang MS. Strategic utilization of consumer value in the service industry: focused on buildup of the community having the same service value. Journal of the Aviation Management Society of Korea, 1: 85-102, 2003.

Inman JJ, Zeelenberg M. Regret in repeat purchase versus switching decisions: the attenuating role of decision justifiability. Journal of Consumer Research, 29: 116-128, 2002.

Jeong HS, Bae SW, Yum CS. The effects of the relationship marketing strategy of online shopping mall on relationship continuity intention via customer satisfaction. Journal of the Korea Management Engineers Society, 23: 21-3, 2018.

Khalifa M, Liu V. Online consumer retention: contingent effects of online shopping habit and online shopping experience. European Journal of Information Systems, 16: 780-792, 2007.

Kim JS, Kang HG. The effects of emotions elicited by images in SNS on online behaviors. The Journal of Information Systems, 28: 199-221, 2012.

Kim JT. Changes in the Retail Industry during the COVID-19 Era. Food Industry and Nutrition, 26: 9-11, 2021a.

Kim MJ. Effects of awareness of negative leadership on job satisfaction and intention to change jobs for estheticians of skin care salons. Asian Journal of Beauty and Cosmetology, 19: 89-100, 2021b.

Lee GN, Shin SY. Purchase behaviors on imported fashion luxury brand's bag according to the types of consumption values of female consumers in 20's and 30's. Fashion and Textile Research Journal, 14: 554-566, 2012.

Lee MW, You JE. The socio-economic effects of COVID-19: focusing on consumer expenditure and labor market. AsiaPacific Journal of Business \& Commerce, 12: 121-141, 2020.

Lee YJ, Cha MG. Antecedents and consequences of negative consumption emotion: focused on the regret and disappointment. Journal of Consumer Studies, 16: 103127, 2005.

Oh YJ. Cosmetic company's eco-friendly activities on consumers' purchase intention through the mediating effects of perceived image. Asian Journal of Beauty and Cosmetology, 18: 149-16, 2020.

Park BJ, Kim SW. A study on the consumption value, brand identification, consumer-brand relationship of KoreanJapanese University consumers: focused on the famous brand. Journal of Consumer Studies, 17: 113-143, 2006.

Park YM, Kim HY. A study on changes in women's makeup interest and use patterns before and after the outbreak of COVID-19. Asian Journal of Beauty and Cosmetology, 19: 129-138, 2021.

Pieters R, Zeelenberg M. A theory of regret regulation 1.1. Journal of Consumer Psychology. 17: 29-35, 2007.

Rokeach M. The nature of human values. Free Press, New York, pp5-11, 1973.

Szymanski DM, Hise RT. E-satisfaction: an initial examination. Journal of Retailing, 76: 309-322, 2000.

Sheth JN, Newman BI, Gross BL. Why we buy what we buy: A theory of consumption values. Journal of Business Research, 61: 159-170, 1991.

Simonson I. The influence of anticipating regret and responsibility on purchase decision. Journal of Consumer Research, 19: 105-118, 1992.

Son HJ, YOU SH, Park CH. Relationship between consumers' exploring cosmetics information behavior and satisfaction and recommendation intention. Asian Journal of Beauty and Cosmetology, 17: 499-509, 2019.

Song MS. What semiotic values do cosmetics consumers consume?: analysis of cosmetic brand reputation and brand selection attributes using text mining. Asian Journal of Beauty and Cosmetology, 19: 263-275, 2021.

Szymanski DM, Hise RT. E-satisfaction: an initial examination. Journal of Retailing, 76: 309-322, 2000.

Tsiros M, Mittal V. Regret: a model of its antecedents and 
consequences in consumer decision making. Journal of Consumer Research, 4: 401-417, 2000.

Won JH, Chung JE. The segmentation of single-person households based on Sheth's theory of consumption values. Journal of Consumer Studies, 26: 73-99, 2015.

ZeithamI VA. Consumer perceptions of price, quality, and value:
A means-end model and synthesis of evidence. Journal of Marketing, 52: 2-22, 1988.

ZeithamI VA, Berry LL, Parasuranman A. The behavioral consequences of service quality. The Journal of Marketing, 60: 31-46, 1996. 


\section{국문초록}

\section{COVID-19 시대에 소비자 소비 가치와 심리상태가 화장품 재구매행동에 미치는 영향}

이지영 ${ }^{1}$, 이정민 ${ }^{2}$, 안성관 ${ }^{1 *}$

${ }^{1}$ 건국대학교 화장품공학과, 서울, 한국

2(주네이쳐블루, 인천, 한국

목적: 본 연구는 코로나 19 로 인한 화장품 소비자의 일상생활 변화가 소비 가치에 따른 행동 의도에 미치는 영향을 조사하고, 화장 품 소비자의 소비 가치, 구매만족도, 재구매의도 간의 관계를 분석하였다. 방법: 본 연구에서는 수집된 설문지를 통계 처리하여 확 립된 가설을 검증하고 데이터 코딩 과정을 거쳐 Statistical Package for Social Science (SPSS) 22.0 프로그램과 Amos 21.0을 이용 하여 실증분석을 수행하였다. 결과: 화장품 쇼핑가치가 만족도와 예상된후회에 미치는 영향을 검증한 결과 독립변수별로는 진귀적 소비가치(C.R.=5.199), 쾌락적 소비가치(C.R.=6.974), 기능적 소비가치(C.R.=4.214)가 만족도에, 윤리적소비가치(C.R.=15.628) 와 기능적소비가치(C.R=2.798)가 예상된 후회에 영향을 미치는 것으로 나타났다( $p\langle 0.01)$. 가설 검증 결과 가장 큰 영향력을 미치는 구간은 만족도가 재구매에 미치는 영향(C.R. $=27.117)$ 으로 나타났다. 이는 진귀적 소비가치, 윤리적 소비가치, 사회적 소비가치, 기 능적 소비가치, 쾌락적 소비가 높을수록 만족도는 높아졌고, 예상된 후회에 미치는 영향력에 대한 분석에서는 윤리적 소비가치, 기 능적 소비가치가 높을수록 예상된 후회는 증가한다는 것으로 이해된다. 또한, 재구매에 미치는 영향력의 경우 만족도와 후회가 모 두 영향력을 미치며, 만족도와 후회가 높을수록 재구매는 증가하는 것으로 이해가 된다. 결론: 본 연구는 1.059 명의 데이터를 분석 하여 언택트시대 영향으로 소비의 중심이 오프라인에서 온라인으로 급격하게 이동하며 나타난 소비가치의 변화가 소비자의 만족에 미치는 영향을 확인함으로써 화장품소비가치을 세분화하여 표적 고객에 맞는 효과적인 전략기술을 수립하는 데에 도움이 될 것이 라 사료된다.

핵심어: 소비가치, 코로나19, 예상된 후회, 재구매행동, 만족

\section{참고문헌}

김문주. 피부미용사의 부정적 리더십 지각이 직무 만족도와 이직 의도에 미치는 영향에 대한 연구. 아시안뷰티화장품학술 지, 19: 89-100, 2021

김지선, 강현정. SNS 상 이미지에 대한 감정이 온라인 행위에 미치는 영향. 정보시스템연구, 4: 199-221, 2012.

김진태. 코로나19 시대의 유통산업의 변화. 식품산업과 영양, 26: 9-11, 2021.

박배진, 김시월. 한·일 대학생 소비자의 소비가치, 브랜드동일시와 소비자-브랜드 관계 연구: 유명브랜드를 중심으로. 소 비자학연구, 17: 113-143, 2006.

박윤미, 김휘율. 코로나 19 (COVID-19) 발생 이전·이후의 여성 화장 관심도 및 화장품 사용실태 변화 분석. 아시안뷰티화 장품학술지, 19: 129-138, 2021.

손효정, 유선희, 박초희. 소비자의 화장품 정보탐색행동과 만족도 및 추천의도의 관계 연구. 아시안뷰티화장품학술지, 17 : 499-509, 2019.

송만석. 화장품 소비자는 어떤 기호가치로 소비를 하는가?: 텍스트 마이닝을 이용한 화장품 브랜드 평판과 브랜드 선택속 성 분석. 아시안뷰티화장품학술지, 19: 263-275, 2021.

원종현, 정재은. 소비가치에 따른 1 인 가구 세분화와 구매행동: Sheth의 소비가치이론을 중심으로. 소비자학연구, 26: 73-99, 2015.

오유진. 화장품 기업의 친환경활동이 지각된 이미지를 매개로 화장품 구매의도에 미치는 영향. 아시안뷰티화장품학술지, 18: 149-161, 2020. 
이가나, 신수연. 20-30대 여성 소비자들의 소비가치 유형에 따른 해외 패션명품 브랜드 가방 구매행동. 한국의류산업학회 지. 4: 554-566, 2012.

이민우, 유지은. 코로나-19의 사회경제적 영향: 소비지출과 노동시장을 중심으로. 아태경상저널, 12: 121-141, 2020 이유재, 차문경 .부정적 소비감정의 선행요인과 결과변수에 대한 연구: 후회감, 실망감을 중심으로. 소비자학연구, 4 : 103-127, 2005.

정희선, 배상욱, 염창선. 온라인 쇼핑몰의 관계마케팅전략이 고객만족을 매개로 관계지속의도에 미치는 영향. 한국경영공 학회지, 23: 21-3, 2018.

최원선. 럭셔리 패션브랜드 비주얼 머천다이징의 표현 특성 및 경향. 기초조형학연구, 21: 383-399, 2020.

하환호, 이영일. 상품구색에 따른 선택어려움과 예상된 후회감이 구매연기의도에 미치는 영향. 상품학연구, 29: 1-10, 2011.

홍성태, 강명수. 서비스 산업에서 소비자 가치의 전략적 활용방안: 서비스 가치에 의한 커뮤니티 형성 전략을 중심으로. 한 국항공경영학회지, 1: 85-102, 2003.

홍성연, 남미우. 팬데믹 시대의 럭셔리 패션 브랜드의 지속가능경영 연구. 한국과학예술융합학회지, 39: 519-537, 2021. 황경희, 김현채. COVID-19로 변화된 식생활 트렌드가 소비가치와 행동의도에 미치는 영향. Tourism Research, 45: 705-72, 2020. 


\section{中文摘要}

\section{COVID-19时代消费者消费价值和心理状态对化妆品回购行为的影响}

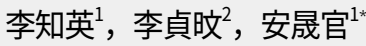

建国大学化妆品学科, 首尔, 韩国

${ }^{2}$ (株) Nature Blue，仁川，韩国

目的: 本研究以消费价值为依据, 考察了新冠病毒对化妆品消费者日常生活的影响, 并分析了化妆品消费者的 消费价值、购买满意度和再购买意愿之间的关系。方法：对收集的问卷进行统计处理，以验证已建立的假设， 并通过数据编码过程, 使用SPSS（社会科学统计软件包）22.0程序和Amos 21.0进行实证分析。结果：作为考 察化妆品购物价值对满意度和预期后悔影响的结果，通过自变量，稀有消费价值（CR=5.199）、享乐消费价 值 $(C R=6.974)$ 和功能性消费价值（CR=4.214）对满意度的影响, 道德消费价值 $(C R=15.628)$ 和功能消费价值 $(C R=2.798)$ 被发现对预期后悔有影响 $(p<0.01)$ 。作为假设检验的结果, 最有影响的部分是满意度对回购的影响 (C.R.=27.117)。随着稀有消费价值、伦理消费价值、社会消费价值、功能性消费价值、享乐消费价值的提升， 满意度也随之提高。据了解, 经历过的后悔也越来越多。另外, 在影响回购的情况下, 满意和后悔都有影响, 据了解, 满意和后悔越高, 回购率越高。结论: 本研究分析了1059人的数据, 证实了消费价值的变化对消费者满 意度的影响, 因为受非现实时代的影响, 消费中心从线下迅速转向线上。人们认为, 这种理解将有助于建立有 效的战略技术。

关键词：消费价值，Covid-19，预期后悔，回购行为，满意 
